\title{
Association between diet and measures of arterial stiffness in type 1 diabetes - Focus on dietary patterns and macronutrient substitutions
}

\section{FinnDiane Study Grp}

2018-11

FinnDiane Study Grp 2018 , ' Association between diet and measures of arterial stiffness in type 1 diabetes - Focus on dietary patterns and macronutrient substitutions ' , Nutrition, Metabolism and Cardiovascular Diseases , vol. 28 , no. 11 , pp. 1166-1172 . https://doi.org/10.1016/j.numecd.2018.0

http://hdl.handle.net/10138/267613

https://doi.org/10.1016/j.numecd.2018.07.003

publishedVersion

Downloaded from Helda, University of Helsinki institutional repository.

This is an electronic reprint of the original article.

This reprint may differ from the original in pagination and typographic detail.

Please cite the original version. 


\title{
Association between diet and measures of arterial stiffness in type 1 diabetes - Focus on dietary patterns and macronutrient substitutions
}

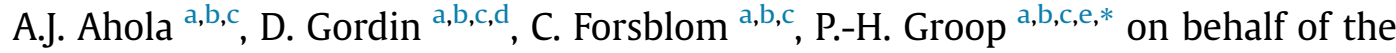 \\ FinnDiane Study Group \\ ${ }^{a}$ Folkhälsan Institute of Genetics, Folkhälsan Research Center, Helsinki, Finland \\ ${ }^{b}$ Abdominal Center Nephrology, University of Helsinki and Helsinki University Central Hospital, Helsinki, Finland \\ ${ }^{c}$ Research Program Unit, Diabetes and Obesity, University of Helsinki, Finland \\ ${ }^{d}$ Dianne Nunnally Hoppes Laboratory Section of Vascular Cell Biology, Joslin Diabetes Center, Harvard Medical School, Boston, USA \\ ${ }^{e}$ Department of Diabetes, Central Clinical School, Monash University, Melbourne, Victoria, Australia \\ Received 27 March 2018; received in revised form 13 June 2018; accepted 9 July 2018 \\ Handling Editor: A. Siani \\ Available online 17 July 2018
}

\section{KEYWORDS \\ Arterial stiffness; \\ Dietary patterns; \\ Macronutrient \\ substitution; \\ Type 1 diabetes}

\begin{abstract}
Background and aims: Increased arterial stiffness contributes to diabetic vascular complications. We identified dietary factors related to arterial stiffness in individuals with type 1 diabetes, a population with high risk of cardiovascular disease.

Methods and results: Altogether, 612 participants ( $40 \%$ men, mean \pm standard deviation age $45 \pm 13$ years) completed a validated diet questionnaire and underwent measurements of arterial stiffness. Of these, 470 additionally completed a food record. Exploratory factor analysis was applied to identify dietary patterns from the diet questionnaires, and nutrient intakes were calculated from food record entries. Arterial stiffness was measured by applanation tonometry. Of the seven dietary factors formed, the factor scores of "Full-fat cheese and eggs" and "Sweet" patterns were negatively associated with measures of arterial stiffness. In the multivariable macronutrient substitution models, favouring carbohydrates over fats was associated with higher aortic mean arterial pressure and aortic pulse wave velocity. When carbohydrates were consumed in place of proteins, higher aortic pulse pressure, aortic mean arterial pressure, and augmentation index were recorded. Replacing energy from alcohol with proteins, was associated with lower aortic pulse pressure, aortic mean arterial pressure, and augmentation index. Relative distributions of dietary fatty acids were neutral with respect to the measures of arterial stiffness. Conclusion: The macronutrient distribution of the diet is likely to affect the resilience of the arteries. Our observations suggest that reducing energy intake from carbohydrates and alcohol may be beneficial. These observations, especially those dealing with dietary patterns, need to be confirmed in a longitudinal study.

๑) 2018 The Italian Society of Diabetology, the Italian Society for the Study of Atherosclerosis, the Italian Society of Human Nutrition, and the Department of Clinical Medicine and Surgery, Federico II University. Published by Elsevier B.V. All rights reserved.
\end{abstract}

\footnotetext{
* Corresponding author. Folkhälsan Research Center, University of Helsinki, PO Box 63, 00014, Finland.

E-mail address: per-henrik.groop@helsinki.fi (P.-H. Groop).
} 


\section{Introduction}

Stiffening of the arteries precedes manifest hypertension, significantly contributes to the development of cardiovascular disease (CVD), and is an independent predictor of all-cause mortality [1]. Individuals with type 1 diabetes (T1D) have high risk of both CVD and mortality [2]. We have previously shown that diabetic nephropathy is not only associated with increased arterial stiffness [3], but also increases the risk of premature death in individuals with T1D [4]. Importantly, even nephropathy-free individuals with T1D exhibit signs of arterial stiffening compared to non-diabetic controls [3]. Due to the early manifestation of such changes in the vasculature, it is important to identify modifiable risk factors.

Diet has the potential to influence arterial stiffness. Amongst the beneficial dietary components are omega-3 fatty acids, soy isoflavones, and bioactive peptides, while limited but consistent evidence suggests that sodium chloride and acute caffeine consumption may be harmful $[5,6]$. The health effects related to food intake, however, likely extend beyond those of isolated nutrients or food items. Indeed, to better capture the complexity of the dietary intake, the role of dietary patterns in vascular health has also been investigated. Here, Mediterranean diet interventions, for example, have been shown to improve endothelial function [7] and reduce the incidence of major cardiovascular events [8]. Instead, Western type of diet, high in carbohydrates, fats, and red meat, but low in fruits and vegetables, has typically proven more detrimental to the vasculature [9]. Finally, along with the renaissance of the Atkins' ideology and increase in the popularity of the low-carbohydrate high-fat diets, there has also been some interest in the role of macronutrient distribution on vascular health. In their review of studies investigating the effects of diets on the vascular integrity, differing in carbohydrate and fat distributions, Gregory et al. found no clear difference between high-carbohydrate and high-fat diets [10]. Instead, they concluded that the amount of literature is sparse and further investigation is necessary. Interestingly, in two more recent papers, similarly conflicting results were presented, as one study reported increased arterial stiffness in response to a highcarbohydrate diet [11], whereas another study connected compromised vascular reactivity to high fat and high protein intakes [12].

The aim of this study was to identify dietary components associated with arterial stiffness among individuals with T1D. As measures of dietary exposure, we used factor analysis-derived dietary patterns, and macronutrient substitutions.

\section{Methods}

\section{Study population}

The study subjects, in these cross-sectional analyses, were individuals with T1D participating in the nationwide Finnish Diabetic Nephropathy (FinnDiane) Study. T1D was assumed if age at onset was $<35$ years and permanent insulin treatment was initiated within one year of the diagnosis. Measures of arterial stiffness have been obtained from a number of participants investigated at the Helsinki University Hospital $(n=867)$. Of these individuals, we included those with an estimated glomerular filtration rate $(e G F R) \geq 30 \mathrm{ml} / \mathrm{min} / 1.73 \mathrm{~m}^{2}$, who had either completed a diet questionnaire $(n=612)$ or a food record with plausible energy intake $(n=470)$. The study was conducted according to the Declaration of Helsinki and the protocol was approved by the Ethics Committee of the Helsinki and Uusimaa Hospital District. The study subjects provided written informed consent prior to participation.

\section{FinnDiane Study visit}

At the FinnDiane Study visit, the participants' height and weight were measured in light clothing. These measurements were used to calculate body mass index (BMI; kg/ $\mathrm{m}^{2}$ ). Early morning blood samples were drawn for creatinine, lipid, lipoprotein, and $\mathrm{HbA}_{1 \mathrm{c}}$ analyses, completed at the central laboratory of the Helsinki University Hospital. As study participants were individuals with T1D, fasting was not required. A light breakfast was allowed in order to prevent or treat hypoglycaemia. The eGFR was calculated using serum creatinine and the CKD-EPI formula [13]. Individuals with significant renal impairment (eGFR $<30 \mathrm{ml} / \mathrm{min} / 1.73 \mathrm{~m}^{2}$ ) were excluded due to the wellknown effect of severe renal disease on the vasculature and on the diet. Smoking was self-reported, and current and non-smokers were distinguished.

\section{Arterial stiffness}

Following a minimum of 5-min rest, arterial stiffness was assessed with applanation tonometry (SphygmoCor; Atcor Medical, Sydney, Australia). Applanation tonometry is a non-invasive method to measure arterial stiffness. We recorded the pulse wave from the radial artery of the right arm, using a high-fidelity micromanometer (SPT-301; Millar Instruments, Texas, USA). From these recordings, the SphygmoCor software created a model of the central pressure waveform, and calculated the heart rate-adjusted augmentation index. For measuring arterial stiffness in the large and intermediate-sized arteries, carotid-femoral and carotid-radial pulse wave velocity (PWV) pressure waveforms were recorded sequentially at the carotid, femoral, and radial arteries. With a simultaneous ECG recording of the $\mathrm{R}$ wave as the reference frame, the software calculated the PWV. Median of three measurements was used in the analyses.

\section{Dietary intake}

Two separate methods to study dietary intake, in the FinnDiane Study, are used. First participants completed a structured diet questionnaire and thereafter a 3-day food record twice. Embedded in the validated [14] diet 
questionnaire was a food frequency questionnaire (FFQ), including 19 most common foods consumed in Finland (fish dishes, meat dishes, poultry, sausages and cold cuts, eggs, legumes, fresh vegetables, cooked vegetables, potatoes, pasta and rice, fruits and berries, full-fat cheese, low-fat cheese, yoghurt and curd, ice cream, soft drinks, sweet pastries, sweets and chocolate, and fried foods). The participants reported the consumption frequencies of these items on a seven-level scale ranging from multiple times per day to never. These entries were transformed into pseudo-continuous variables describing the monthly consumption (i.e. "once a day" was recoded as "28", and "once a week" as " 4 "). The recoded values were submitted to factor analysis. The two food records, each comprising 2 week day and one weekend day, were allocated with a 10week interval in order to capture seasonal variation in the dietary intake. The participants were instructed to report in detail all foods and drinks consumed over the recordkeeping days. Emphasis was put on keeping the dietary practises as habitual as possible. Energy and macronutrient intakes were calculated using AivoDiet software (version 2.0.2.3, AIVO, Turku, Finland). Data from individuals with a minimum of 3 days of food records, reporting a mean daily energy intake between $5021 \mathrm{~kJ}$ and $14,644 \mathrm{~kJ}(1200-3500 \mathrm{kcal})$, were included in the analyses.

\section{Statistical analyses}

Descriptive statistics are reported as percentages for categorical data, mean \pm standard deviation for parametric continuous data, and median (interquartile range) for nonparametric continuous data. Spearman's rank correlation coefficient was calculated to investigate the correlations between the dietary variables and the measures of arterial stiffness.

Underlying dietary patterns, from the FFQ were identified using exploratory factor analysis (maximal likelihood and varimax rotation). The number of factors identified was based on eigenvalues $>1.0$, and items with a factor loading $|\geq 0.20|$ with a particular factor, were included. The factor score was the sum of the scores for all items associated with that particular factor multiplied by its corresponding factor loading. These factor scores were treated as continuous variables in the generalized linear regression analyses when investigating their associations with the measures of arterial stiffness.

The independent associations between macronutrient intakes and arterial stiffness were investigated using nutrient density substitution models. Here, one macronutrient (per $5 \mathrm{E} \%$ ) at a time was treated as an independent variable in the generalised linear regression analysis. Selected confounding variables, total energy intake, and all but one of the remaining macronutrients were entered as covariates. The obtained results can be interpreted as a change in the outcome variable (arterial stiffness), when energy intake from the independent macronutrient is increased by $5 \mathrm{E} \%$ at the expense of the macronutrient that was omitted from the model.
A two-tailed $P$ value $<0.05$ was considered statistically significant. All data were analysed using IBM SPSS Statistics for Windows, Version 22.0 (IBM Corp, Armonk, NY, USA).

\section{Results}

Altogether, 612 individuals completed the diet questionnaire, and 470 submitted food records with plausible energy intake (Table 1). Of these $93 \%$ and $95 \%$, respectively, had eGFR values at the range of normal/high or mildly decreased $\left(\geq 60 \mathrm{ml} / \mathrm{min} / 1.73 \mathrm{~m}^{2}\right)$. Due to the low number of individuals with eGFR values in the range of $30-59 \mathrm{ml} /$ $\min / 1.73 \mathrm{~m}^{2}$, data were analysed pooled. However, eGFR was included as a cofactor.

\section{Dietary patterns}

Using factor analysis, seven dietary patterns were identified and intuitively named, based on the included food items (Table 2). The correlations between the factor scores and measures of arterial stiffness are shown in Supplementary Table 1 . In the multivariable model, the factor scores of the "Full-fat cheese and eggs" diet pattern, were negatively associated with aortic pulse pressure and aortic mean arterial pressure (Table 3). The "Sweet" pattern's factor scores were negatively associated with aortic pulse pressure, aortic mean arterial pressure, and

Table 1 Characteristics of the study population having completed the diet questionnaire, and the food record.

\begin{tabular}{|c|c|c|}
\hline & $\begin{array}{l}\text { Diet questionnaire } \\
(\mathrm{n}=612)\end{array}$ & $\begin{array}{l}\text { Food record } \\
(\mathrm{n}=470)\end{array}$ \\
\hline Men, \% & 40.2 & 37.7 \\
\hline Age, years & $43.9(34.8-55.1)$ & $43.7(34.6-55.4)$ \\
\hline $\begin{array}{l}\text { Diabetes duration, } \\
\text { years }\end{array}$ & $25.9(16.4-38.6)$ & $25.2(15.3-38.3)$ \\
\hline Current smoking, \% & 10.4 & 9.2 \\
\hline BMI, $\mathrm{kg} / \mathrm{m}^{2}$ & $25.2(23.0-28.3)$ & $25.3(23.1-28.4)$ \\
\hline Total cholesterol, mmol/l & $4.5(4.0-5.0)$ & $4.5(4.0-5.0)$ \\
\hline HDL-cholesterol, mmol/l & $1.57(1.31-1.90)$ & $1.58(1.33-1.93)$ \\
\hline Triglycerides, mmol/l & $0.92(0.70-1.26)$ & $0.91(0.69-1.24)$ \\
\hline $\mathrm{HbA}_{1 \mathrm{c}}, \mathrm{mmol} / \mathrm{mol}$ & $63(56-72)$ & $63(55-71)$ \\
\hline $\mathrm{HbA}_{1 \mathrm{c}}, \%$ & $7.9(7.2-8.7)$ & $7.9(7.2-8.7)$ \\
\hline $\begin{array}{l}\text { eGFR } \geq 60 \mathrm{ml} / \mathrm{min} \text { per } \\
\quad 1.73 \mathrm{~m}^{2}, \%\end{array}$ & 93.1 & 94.7 \\
\hline Heart rate, bpm & $65(59-73)$ & $65(59-72)$ \\
\hline Brachial SBP, mmHg & $133(122-145)$ & $132(121-144)$ \\
\hline Brachial DBP, mmHg & $74(69-80)$ & $74(69-80)$ \\
\hline Aortic SBP, mmHg & $119(108-131)$ & $119(108-130)$ \\
\hline Aortic DBP, mmHg & $75(70-82)$ & $74(69-81)$ \\
\hline $\begin{array}{l}\text { Aortic pulse pressure, } \\
\text { mmHg }\end{array}$ & $41(34-55)$ & $41(34-55)$ \\
\hline $\begin{array}{l}\text { Aortic mean arterial } \\
\text { pressure, } \mathrm{mmHg}\end{array}$ & 90 (84-97) & $90(83-97)$ \\
\hline Augmentation index, \% & $8(3-13)$ & $8(4-13)$ \\
\hline $\begin{array}{l}\text { Aortic pulse wave } \\
\text { velocity, m/s }\end{array}$ & $8.1(6.5-10.3)$ & $7.8(6.4-10.0)$ \\
\hline
\end{tabular}


Table 2 Dietary patterns derived from factor analysis of the FFQ section of the diet questionnaire $(\mathrm{n}=612)$.

\begin{tabular}{|c|c|c|c|c|}
\hline Pattern & Eigenvalue & $\begin{array}{l}\% \text { of } \\
\text { variance }\end{array}$ & $\begin{array}{l}\text { Included food } \\
\text { items }\end{array}$ & $\begin{array}{l}\text { Factor } \\
\text { loadings }\end{array}$ \\
\hline \multirow{3}{*}{$\begin{array}{l}\text { Full-fat cheese } \\
\text { and eggs }\end{array}$} & \multirow[t]{3}{*}{2.254} & \multirow[t]{3}{*}{11.862} & Full-fat cheese & 0.971 \\
\hline & & & Eggs & 0.334 \\
\hline & & & Low-fat cheese & -0.324 \\
\hline \multirow[t]{5}{*}{ Sweet } & \multirow[t]{5}{*}{1.890} & \multirow[t]{5}{*}{9.948} & $\begin{array}{l}\text { Sweets and } \\
\text { chocolate }\end{array}$ & 0.656 \\
\hline & & & Sweet pastry & 0.643 \\
\hline & & & Yoghurt & 0.335 \\
\hline & & & Low-fat cheese & 0.259 \\
\hline & & & Ice cream & 0.216 \\
\hline \multirow[t]{5}{*}{ Healthy snack } & \multirow[t]{5}{*}{1.712} & \multirow[t]{5}{*}{9.013} & $\begin{array}{l}\text { Fruits and } \\
\text { berries }\end{array}$ & 0.660 \\
\hline & & & Yoghurt & 0.444 \\
\hline & & & Fresh vegetables & 0.440 \\
\hline & & & $\begin{array}{l}\text { Cooked } \\
\text { vegetables }\end{array}$ & 0.202 \\
\hline & & & Soft drinks & -0.330 \\
\hline \multirow{7}{*}{$\begin{array}{c}\text { Legumes and } \\
\text { vegetables }\end{array}$} & \multirow[t]{7}{*}{1.479} & \multirow[t]{7}{*}{7.782} & Legumes & 0.606 \\
\hline & & & $\begin{array}{l}\text { Cooked } \\
\text { vegetables }\end{array}$ & 0.556 \\
\hline & & & Fresh vegetables & 0.351 \\
\hline & & & Eggs & 0.267 \\
\hline & & & Fried dishes & 0.217 \\
\hline & & & Ice cream & 0.216 \\
\hline & & & $\begin{array}{l}\text { Fruits and } \\
\text { berries }\end{array}$ & 0.204 \\
\hline \multirow{3}{*}{$\begin{array}{l}\text { Meat and } \\
\text { potatoes }\end{array}$} & \multirow[t]{3}{*}{1.310} & \multirow[t]{3}{*}{6.896} & Meat dishes & 0.756 \\
\hline & & & Potatoes & 0.514 \\
\hline & & & $\begin{array}{l}\text { Sausages and } \\
\text { cold cuts }\end{array}$ & 0.281 \\
\hline Pasta and rice & 1.158 & 6.097 & Pasta and rice & 0.938 \\
\hline \multirow[t]{4}{*}{ Modern } & \multirow[t]{4}{*}{1.049} & \multirow[t]{4}{*}{5.520} & Poultry & 0.515 \\
\hline & & & Fried foods & 0.334 \\
\hline & & & Meat dishes & 0.329 \\
\hline & & & Pasta and rice & 0.300 \\
\hline
\end{tabular}

Eigen values are the variances of the factors; \% of variance represent the per cent of total variance accounted by each factor; factor loadings show the correlation of each food item with the given dietary pattern.

augmentation index. The "Modern" factor scores were negatively associated with aortic pulse wave velocity.

\section{Energy and macronutrients}

Carbohydrates provided the majority of dietary energy, followed by fats, proteins, and alcohol (Table 4). The correlations between macronutrient intakes and the measures of arterial stiffness are shown in Supplementary Table 1. In the multivariable macronutrient substitution model, favouring carbohydrates over fats was associated with higher aortic mean arterial pressure and aortic pulse wave velocity (Table 5). These results may also be interpreted reversely, thus increasing fat intake at the expense of carbohydrates is associated with lower mean arterial pressure and aortic pulse wave velocity. Favouring carbohydrates over proteins was related to higher aortic pulse pressure, aortic mean arterial pressure, and augmentation index, while favouring fats over proteins was associated with higher augmentation index. Reducing energy intake from alcohol while increasing that of proteins was associated with lower aortic pulse pressure, aortic mean arterial pressure, and augmentation index. The relative distributions of fatty acids were not associated with the measures of arterial stiffness. The significant results from the macronutrient substitutions are also presented in the Supplementary Fig. 1.

\section{Discussion}

As indirect markers of arterial stiffness we measured aortic pulse wave velocity, augmentation index, aortic mean arterial pressure, and aortic pulse pressure from individuals with T1D and investigated the association between these markers and dietary intake. With respect to the dietary intake, our approach was twofold; we explored both dietary patterns and macronutrient substitutions. Of the seven dietary patterns formed, the "Full-fat cheese and eggs", and "Sweet" were associated with better vascular health. Analyses of the macronutrients revealed that substituting carbohydrates for either fats or proteins was associated with elevated arterial stiffness. Increasing energy intake from proteins at the expense of alcohol, on the other hand, was beneficial for the vasculature.

While the above results dealing with the "Sweet" pattern and carbohydrate intake, may seem conflicting at first sight, important distinctions between the methods used to measure these variables need to be acknowledged. The questionnaire, used to identify dietary patterns, measures how frequently the participants have consumed the given food items over the period of the previous month. Instead, the food record provides more detailed information of the actual amounts of foods consumed over

Table 3 Associations between dietary patterns and measures of arterial stiffness $(n=612)$.

\begin{tabular}{lllll}
\hline & Aortic pulse pressure & Aortic mean arterial pressure & Augmentation index & Aortic pulse wave velocity \\
\hline Full-fat cheese and eggs & $-1.59(-2.69 \text { to }-0.48)^{* *}$ & $-1.13(-1.98 \text { to }-0.28)^{* *}$ & $-0.40(-0.85-0.05)$ & $-0.20(-0.50-0.09)$ \\
Sweet & $-1.96(-3.31 \text { to }-0.62)^{* *}$ & $-1.10(-2.14 \text { to }-0.06)^{*}$ & $-0.66(-1.21 \text { to }-0.12)^{*}$ & $-0.14(-0.54-0.26)$ \\
Healthy snack & $0.81(-0.68-2.30)$ & $-0.06(-1.21-1.08)$ & $-0.13(-0.73-0.48)$ & $0.08(-0.36-0.52)$ \\
Legumes and vegetables & $0.16(-1.30-1.62)$ & $-0.62(-1.74-0.50)$ & $-0.18(-0.77-0.42)$ & $-0.02(-0.40-0.36)$ \\
Meat and potatoes & $0.34(-1.02-1.70)$ & $0.37(-0.68-1.42)$ & $0.33(-0.22-0.89)$ & $-0.40(-0.88-0.09)$ \\
Pasta and rice & $-0.09(-1.31-1.13)$ & $-0.44(-1.38-0.50)$ & $-0.18(-0.67-0.32)$ & $-0.09(-0.44-0.26)$ \\
Modern & $-1.03(-2.68-0.62)$ & $-0.39(-1.66-0.88)$ & $-0.22(-0.89-0.45)$ & $-0.50(-0.92 \text { to }-0.07)^{*}$ \\
\hline
\end{tabular}

Generalized linear regression. Data are presented as B (95\% CI). All models are adjusted for age, sex, eGFR, smoking, body mass index, and other diet factors. ${ }^{*} P<0.05,{ }^{* *} P<0.01,{ }^{* * *} P<0.001$. 
Table 4 Energy, macronutrient, and sucrose intakes of the study population having completed the food record $(n=470)$.

\section{Energy, kJ}

Energy, kcal

Carbohydrate, $g$

Carbohydrate, E\%

Sucrose, $g$

Fat, $\mathrm{g}$

Fat, E\%

Protein, $\mathrm{g}$

Protein, E\%

Alcohol, $g$

Alcohol, E\%

SAFA, E\%

MUFA, E\%

PUFA, E\%
$8010 \pm 1808$

$1914 \pm 432$

$203 \pm 58$

$42 \pm 7$

$37 \pm 20$

$76 \pm 22$

$36 \pm 6$

$80 \pm 22$

$17 \pm 3$

$8 \pm 11$

$3 \pm 4$

$12 \pm 3$

$12 \pm 3$

$6 \pm 2$

To better enable comparison between nutrients, data are presented mean \pm standard deviation although all variables were not normally distributed. E\%, percentage of total energy intake; SAFA, saturated fatty acids; MUFA, monounsaturated fatty acids; PUFA polyunsaturated fatty acids.

the three record-keeping days. Moreover, "sweet food items" are not the sole source of carbohydrates, but they are also obtained from sources such as fruits, berries, vegetables, grains, and milk products. Thus, the data collected with these two methods, and the variables calculated from these data, are not directly comparable.

The association between various dietary patterns and vascular health has previously been investigated. In one of these studies, stiffening of the carotid arteries was associated with lower levels of adherence to the Mediterranean dietary pattern in early life [15]. In a meta-analysis, a low-sodium diet, emphasizing the intake of vegetables, fruits, whole grains, lean meats, and low-fat dairy, revealed a profitable reducing effect on both the systolic and the diastolic blood pressure [16]. In another metaanalysis, adherence to a healthy/prudent dietary pattern was associated with reduced risk of coronary heart disease, while an increased risk was related to a Western diet pattern [9]. Some studies have associated high intake of fruits and vegetables [17] or interventions with plant- derived compounds [18] with reduced levels of arterial stiffness. In contrast, an 18-week intervention with increasing amounts of fruits and vegetables did not improve pulse wave velocity or augmentation index in high CVD risk individuals [19]. Similarly, a 12-month intervention aimed at increasing consumption of fruits, vegetables, and dairy, did not improve arterial stiffness in individuals with diabetes [20].

In the light of the previous observations, our current results dealing with the dietary patterns are somewhat puzzling. Methodological differences between studies may contribute to some of the diverging observations. As previously discussed, in the FFQ only the frequencies of consumption are reported, which may not directly translate to the amounts of foods consumed. Another potential explanation is the use of exploratory factor analysis to form the patterns from the FFQ-entries. That is, unlike in the DASH diet pattern [16] for example, no prior assumptions regarding the food items which should be included in each pattern are made. The differences in the methods aside, we were unable to identify plausible biological mechanisms to explain why the "Full-fat cheese and eggs" and especially the "Sweet" diet patterns would be beneficial to the vasculature. Instead, we argue that our observations may be burdened by the cross-sectional study design, and despite adjusting the models for variables known to be associated with vascular health, residual confounding by factors not taken into account remains a likely explanation.

Fat and saturated fat consumption have traditionally been connected with poor vascular health [21]. In their meta-analyses of prospective studies [22] and randomized controlled trials [23] Harcombe et al. reported, however, that neither total fat nor saturated fat intake is associated with adverse cardiovascular outcomes. In concordance with these reports, substitutions between different fatty acids proved neutral with respect to the measures of arterial stiffness, in the current study. Instead, we observed that increasing fat intake over carbohydrates was associated with lower aortic pulse pressure, aortic mean arterial pressure, and augmentation index, while increasing protein intake over carbohydrates was associated with lower aortic mean

Table 5 Associations between dietary macronutrient intake and measures of arterial stiffness $(n=470)$.

\begin{tabular}{lllll}
\hline $\begin{array}{l}\text { Macronutrient intake } \\
\text { increased (reduced) }\end{array}$ & Aortic pulse pressure & Aortic mean arterial pressure & Augmentation index & Aortic pulse wave velocity \\
\hline CHO (fat) & $0.96(-0.02-1.94)$ & $0.80(0.05-1.54)^{*}$ & $0.14(-0.25-0.52)$ & $0.31(0.01-0.60)^{*}$ \\
CHO (protein) & $2.28(0.36-4.20)^{*}$ & $1.96(0.51-3.42)^{* *}$ & $1.07(0.31-1.82)^{* *}$ & $0.32(-0.19-0.83)$ \\
CHO (alcohol) & $-0.16(-1.79-1.48)$ & $-0.65(-1.89-0.60)$ & $-0.32(-0.97-0.32)$ & $-0.20(-0.73-0.33)$ \\
Fat (protein) & $1.24(-0.74-3.21)$ & $1.14(-0.35-2.63)$ & $0.90(0.13-1.67)^{*}$ & $0.02(-0.48-0.52)$ \\
Fat (alcohol) & $-1.06(-2.82-0.71)$ & $-1.31(-2.65-0.04)$ & $-0.41(-1.10-0.29)$ & $-0.46(-1.01-0.09)$ \\
Protein (alcohol) & $-2.64(-4.99 \text { to }-0.29)^{*}$ & $-2.56(-4.34 \text { to }-0.78)^{* *}$ & $-1.39(-2.31 \text { to }-0.47)^{* *}$ & $-0.51(-1.23-0.20)$ \\
SAFA (MUFA) & $-3.03(-8.02-1.97)$ & $0.19(-3.61-3.99)$ & $-0.73(-2.69-1.22)$ & $0.50(-0.85-1.85)$ \\
SAFA (PUFA) & $-0.59(-4.17-2.99)$ & $0.80(-1.92-3.52)$ & $0.62(-0.78-2.02)$ & $-0.07(-1.01-0.86)$ \\
MUFA (PUFA) & $3.09(-3.37-9.56)$ & $2.36(-2.55-7.27)$ & $2.35(-0.17-4.88)$ & $-0.40(-2.07-1.27)$ \\
\hline
\end{tabular}

Generalized linear regression. Data are presented as B (95\% CI). Models are adjusted for age, sex, eGFR, smoking, and body mass index. In each model, one of the macronutrients is an independent variable, while one of the macronutrients is excluded from the model (mentioned in the parentheses). The remaining macronutrients and total energy intake are covariates. The B represents an increase (if positive) or decrease (if negative) in the measures of arterial stiffness when the intake of the independent macronutrient is increased by $5 \%$ of total energy at the expense of the excluded macronutrient. CHO, carbohydrate; SAFA, saturated fatty acids; MUFA, monounsaturated fatty acids; PUFA, polyunsaturated fatty acids. ${ }^{*} P<0.05,{ }^{* *} P<0.01$. 
arterial pressure, and aortic pulse wave velocity. Our observations are supported by Chan et al. who showed an independent association between a high-carbohydrate diet and increased pulse wave velocity in individuals with established CVD [11]. The precise mechanism through which carbohydrates could contribute to the arterial stiffness is not known. A number of reports have, however, suggested that reducing either carbohydrate intake or the glycaemic load of the diet could be beneficial [24-26]. Amongst others, abundant intake of carbohydrates is related to increased serum triglyceride concentrations and reduced levels of HDL-cholesterol [24,25]. Moreover, a high-carbohydrate diet has been associated with increased blood pressure [11], and increased levels of inflammatory markers [27] and oxidative stress [28].

Finally, increasing energy intake from proteins at the expense of alcohol, was beneficially associated with markers of arterial stiffness, in the current study. We are not aware of any other studies comparing the effects of alcohol and protein intakes on the arterial stiffness. However, in a large cross-sectional study, higher protein intake was associated with lower arterial stiffness [29]. The investigators attributed these beneficial effects to vasoactive amino acids; glutamic acid, leucine, and tyrosine, in particular. Alcohol consumption, on the other hand, increases the risk of hypertension in a dose-dependent manner [30], and is associated with increased arterial stiffness [31].

The strengths of the current study include a large sample of well-characterized participants with T1D, rigorous assessment of arterial stiffness, and use of validated methods to study dietary intake. The cross-sectional design limits us, however, from making conclusions about causality. Moreover, the use of self-report method to study dietary intake may be a source of bias, as the very act of reporting dietary intake likely influences what participants eat over the record-keeping days. Also the replies could be influenced by factors such as social desirability, as food items generally considered unhealthy may have been underreported. Some selection bias may be evident as healthier individuals or those more interested in their health are likely to be over-represented. Upon investigating whether individuals providing and not providing dietary data differed somehow, we observed no difference in age, diabetes duration, smoking, BMI, total cholesterol, glycaemic control, heart rate, aortic pulse pressure, and augmentation index (Supplementary Table 2). However, as we excluded individuals with markedly reduced renal function, the ones not included in the analyses had more frequently diabetic nephropathy. This was also reflected in a higher proportion of men, less favourable HDL-cholesterol and triglyceride panel, higher blood pressure, and higher aortic pulse wave velocity among the excluded individuals. Our observations may not, thus, be generalizable to those with markedly reduced renal function. Finally, despite multivariable modelling, the possibility of residual confounding related to unmeasured confounders cannot be excluded.

With the above limitations in mind, our observations suggest that reducing energy intake from carbohydrate, and replacing it with energy derived from proteins or fats is associated with better vascular health, measured as arterial stiffness, in individuals with type 1 diabetes. A beneficial association was also seen with increased intake of energy from proteins at the expense of alcohol. Importantly, for these observations, reasonable mechanisms could be identified from the literature. Instead, the current results dealing with the dietary patterns should be interpreted with caution as a number of methodological issues may have impacted these observations. The data collected in this study will, however, serve as a baseline for the future analyses where we will investigate the longitudinal associations between dietary intake and vascular health.

\section{Conflicts of interest}

PHG has received research grants from Eli Lilly and Roche, is an advisory board member for AbbVie, Astra Zeneca, Boehringer-Ingelheim, Cebix, Eli Lilly, Janssen, MSD, Medscape, Novartis, Novo Nordisk, and Sanofi. He has received lecture fees from Astra Zeneca, BoehringerIngelheim, Eli Lilly, Elo Water, Genzyme, Medscape, MSD, Novartis, Novo Nordisk, and Sanofi. Other authors declare no conflict of interest.

\section{Acknowledgements}

This work was supported by grants from Academy of Finland; Novo Nordisk Foundation; Signe and Ane Gyllenberg Foundation; The Helsinki University Central Hospital Research Funds; Wilhelm and Else Stockmann Foundation; Päivikki and Sakari Sohlberg Foundation; Diabetes Wellness Finland; The Liv och Hälsa Society; The Medical Society of Finland; The Finnish Medical Foundation; The Biomedicum Helsinki Foundation; The Swedish Cultural Foundation in Finland; and the Dorothea Olivia, Karl Walter och Jarl Walter Perkléns Foundation. Funding agencies played no role in defining the study design, data collection, analysis and interpretation of data, writing of the manuscript, or in the decision to submit the manuscript for publication. The assistance of Anna Sandelin, Jaana Tuomikangas, and Mira Korolainen acknowledged.

\section{Appendix A. Supplementary data}

Supplementary data related to this article can be found at https://doi.org/10.1016/j.numecd.2018.07.003.

\section{References}

[1] Vlachopoulos C, Aznaouridis K, Stefanadis C. Prediction of cardiovascular events and all-cause mortality with arterial stiffness: a systematic review and meta-analysis. J Am Coll Cardiol 2010;55: $1318-27$.

[2] Orchard TJ, Costacou T, Kretowski A, Nesto RW. Type 1 diabetes and coronary artery disease. Diabetes Care 2006;29:2528-38.

[3] Gordin D, Wadén J, Forsblom C, Thorn LM, Rosengård-Bärlund M, Heikkilä $\mathrm{O}$, et al. Arterial stiffness and vascular complications in patients with type 1 diabetes: the Finnish Diabetic nephropathy (FinnDiane) study. Ann Med 2012;44:196-204. 
[4] Groop PH, Thomas MC, Moran JL, Wadén J, Thorn LM, Mäkinen VP, et al. The presence and severity of chronic kidney disease predicts all-cause mortality in type 1 diabetes. Diabetes 2009;58:1651-8.

[5] LaRocca TJ, Martens CR, Seals DR. Nutrition and other lifestyle influences on arterial aging. Ageing Res Rev 2017;39:106-19.

[6] Pase MP, Grima NA, Sarris J. The effects of dietary and nutrient interventions on arterial stiffness: a systematic review. Am J Clin Nutr 2011;93:446-54.

[7] Davis CR, Hodgson JM, Woodman R, Bryan J, Wilson C, Murphy KJA. Mediterranean diet lowers blood pressure and improves endothelial function: results from the MedLey randomized intervention trial. Am J Clin Nutr 2017:105:1305-13.

[8] Estruch R, Ros E, Salas-Salvado J, Covas MI, Corella D, Aros F, et al. Primary prevention of cardiovascular disease with a mediterranean diet. N Engl J Med 2013;368:1279-90.

[9] Zhang XY, Shu L, Si CJ, Yu XL, Liao D, Gao W, et al. Dietary patterns, alcohol consumption and risk of coronary heart disease in adults: a meta-analysis. Nutrients 2015;7:6582-605.

[10] Gregory SM, Headley SA, Wood RJ. Effects of dietary macronutrient distribution on vascular integrity in obesity and metabolic syndrome. Nutr Rev 2011;69:509-19.

[11] Chan HT, Chan YH, Yiu KH, Li SW, Tam S, Lau CP, et al. Worsened arterial stiffness in high-risk cardiovascular patients with high habitual carbohydrate intake: a cross-sectional vascular function study. BMC Cardiovasc Disord 2014;14:24.

[12] Merino J, Kones R, Ferre R, Plana N, Girona J, Aragones G, et al. Low-carbohydrate, high-protein, high-fat diet alters small peripheral artery reactivity in metabolic syndrome patients. Clín Invest Arterioscler 2014;26:58-65.

[13] Levey AS, Stevens LA, Schmid CH, Zhang YL, Castro 3rd AF Feldman $\mathrm{HI}$, et al. A new equation to estimate glomerular filtration rate. Ann Intern Med 2009;150:604-12.

[14] Ahola AJ, Lassenius MI, Forsblom C, Harjutsalo V, Lehto M, Groop PH. Dietary patterns reflecting healthy food choices are associated with lower serum LPS activity. Sci Rep 2017;7:6511.

[15] van de Laar RJ, Stehouwer CD, van Bussel BC, Prins MH, Twisk JW, Ferreira I. Adherence to a Mediterranean dietary pattern in early life is associated with lower arterial stiffness in adulthood: the Amsterdam growth and health longitudinal study. J Intern Med 2013;273:79-93.

[16] Saneei P, Salehi-Abargouei A, Esmaillzadeh A, Azadbakht L. Influence of dietary approaches to stop hypertension (DASH) diet on blood pressure: a systematic review and meta-analysis on randomized controlled trials. Nutr Metab Cardiovasc Dis 2014;24:1253-61.

[17] Aatola H, Koivistoinen T, Hutri-Kahonen N, Juonala M, Mikkilä V, Lehtimaki T, et al. Lifetime fruit and vegetable consumption and arterial pulse wave velocity in adulthood: the cardiovascular risk in young Finns study. Circulation 2010;122:2521-8.

[18] Teede HJ, McGrath BP, DeSilva L, Cehun M, Fassoulakis A, Nestel PJ. Isoflavones reduce arterial stiffness: a placebo-controlled study in men and postmenopausal women. Arterioscler Thromb Vasc Biol 2003;23:1066-71.
[19] Macready AL, George TW, Chong MF, Alimbetov DS, Jin Y, Vidal A, et al. Flavonoid-rich fruit and vegetables improve microvascular reactivity and inflammatory status in men at risk of cardiovascular disease-FLAVURS: a randomized controlled trial. Am J Clin Nutr 2014;99:479-89.

[20] Petersen KS, Clifton PM, Lister N, Keogh JB. Effect of improving dietary quality on arterial stiffness in subjects with type 1 and type 2 diabetes: a 12 months randomised controlled trial. Nutrients 2016:8.

[21] Ascherio A, Rimm EB, Giovannucci EL, Spiegelman D, Stampfer M, Willett WC. Dietary fat and risk of coronary heart disease in men: cohort follow up study in the United States. BMJ 1996;313: 84-90.

[22] Harcombe Z, Baker JS, Davies B. Evidence from prospective cohort studies does not support current dietary fat guidelines: a systematic review and meta-analysis. Br J Sports Med 2017;51: 1743-9.

[23] Harcombe Z, Baker JS, DiNicolantonio JJ, Grace F, Davies B. Evidence from randomised controlled trials does not support current dietary fat guidelines: a systematic review and meta-analysis. Open Heart 2016:3.

[24] Park SH, Lee KS, Park HY. Dietary carbohydrate intake is associated with cardiovascular disease risk in Korean: analysis of the third Korea National Health and Nutrition Examination Survey (KNHANES III). Int J Cardiol 2010;139:234-40.

[25] Lasker DA, Evans EM, Layman DK. Moderate carbohydrate, moderate protein weight loss diet reduces cardiovascular disease risk compared to high carbohydrate, low protein diet in obese adults: a randomized clinical trial. Nutr Metab 2008;5:30.

[26] Brand-Miller J, McMillan-Price J, Steinbeck K, Caterson I. Dietary glycemic index: health implications. J Am Coll Nutr 2009; 28(Suppl):446S-9S

[27] da Silva-Santi LG, Antunes MM, Caparroz-Assef SM, Carbonera F, Masi LN, Curi R, et al. Liver fatty acid composition and inflammation in mice fed with high-carbohydrate diet or high-fat diet. Nutrients 2016:8

[28] Mah E, Noh SK, Ballard KD, Matos ME, Volek JS, Bruno RS, Postprandial hyperglycemia impairs vascular endothelial function in healthy men by inducing lipid peroxidation and increasing asymmetric dimethylarginine: Arginine. J Nutr 2011; 141:1961-8.

[29] Jennings A, MacGregor A, Welch A, Chowienczyk P, Spector T, Cassidy A. Amino acid intakes are inversely associated with arterial stiffness and central blood pressure in women. J Nutr 2015; $145: 2130-8$.

[30] Taylor B, Irving HM, Baliunas D, Roerecke M, Patra J, Mohapatra S, et al. Alcohol and hypertension: gender differences in doseresponse relationships determined through systematic review and meta-analysis. Addiction 2009;104:1981-90.

[31] O'Neill D, Britton A, Brunner EJ, Bell S. Twenty-five-year alcohol consumption trajectories and their association with arterial aging: a prospective cohort study. J Am Heart Assoc 2017;6. 